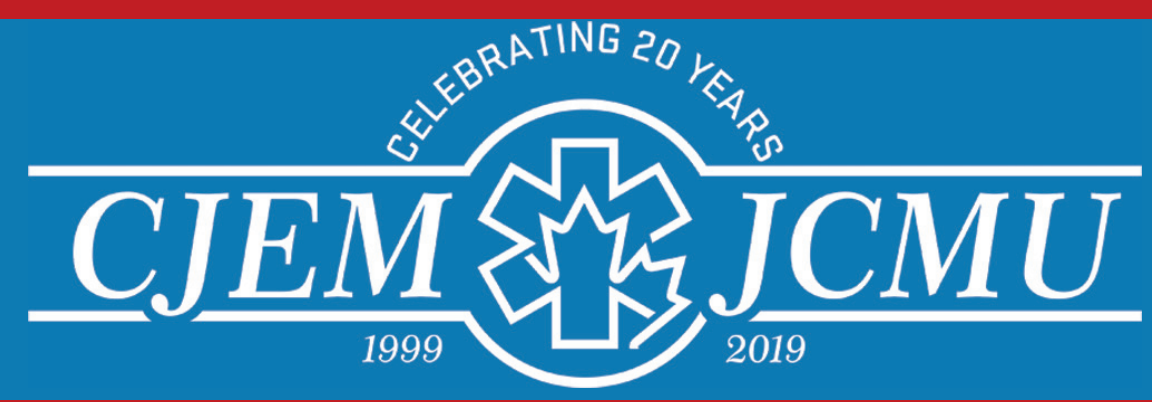

Canadian Journal of Emergency Medicine/Journal canadien de la médecine d'urgence

\title{
Volume 22 Issue 1
}

\section{January 2020/janvier 2020}

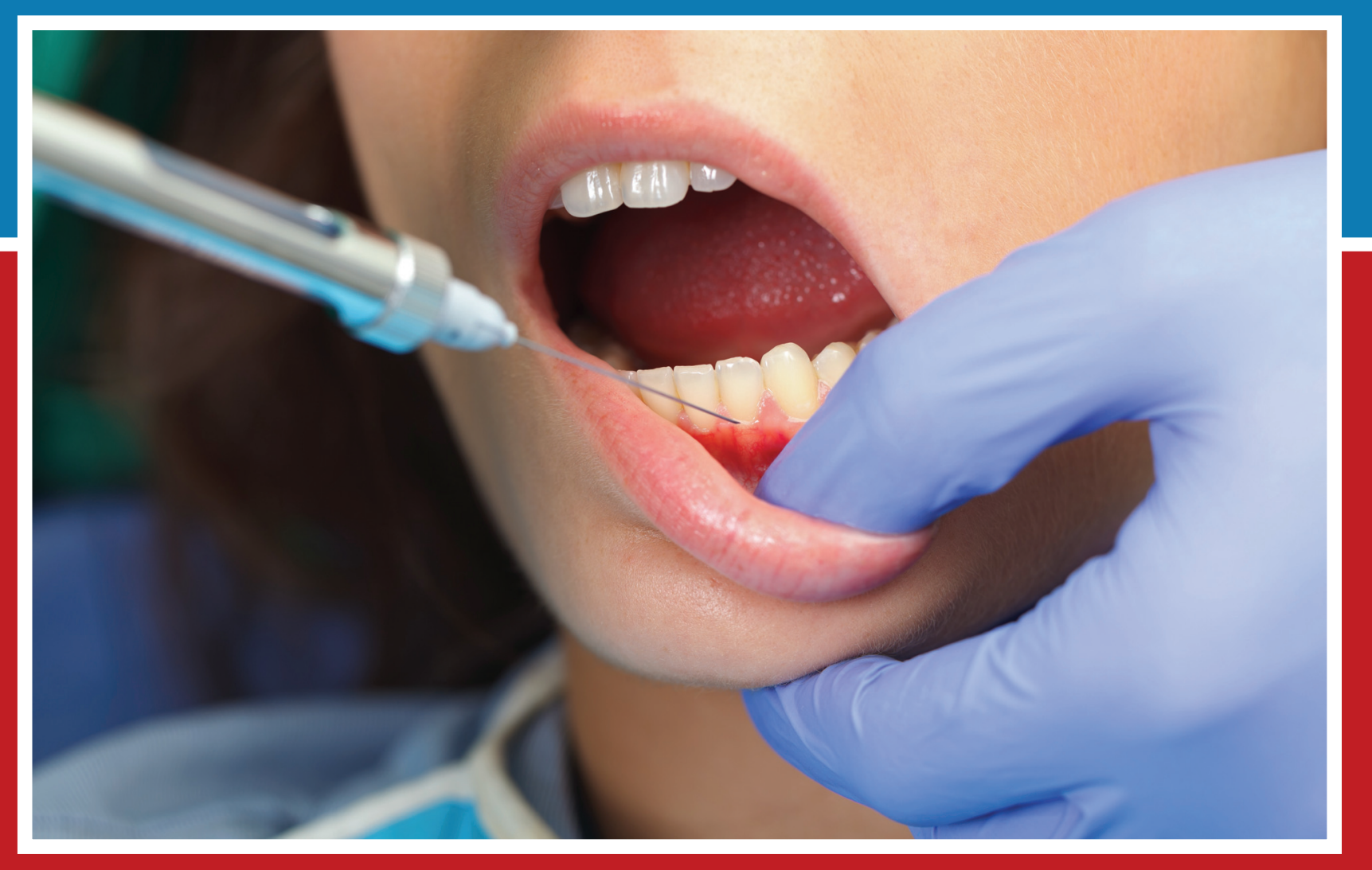

Inspiring excellence in emergency medical care 
DO YOU RECOGNIZE PATIENTS WITH HIDRADENITIS SUPPURATIVA (HS)?

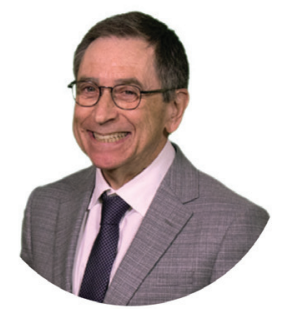

DR. NEIL SHEAR

Head of Dermatology, Sunnybrook Hospital
“People with HS come to the emergency room in severe pain and discomfort requiring assistance with the draining of the boils during a flare-up. It's not unusual for patients to go home undiagnosed."

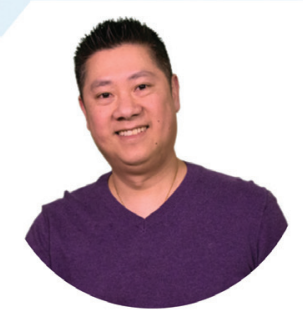

DR. VU KIET TRAN

ER physician at University Health Network

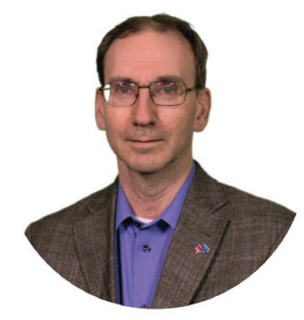

DR. RALPH GEORGE

Associate Professor, University of Toronto, Division of General Surgery

"There is currently no cure for HS. Early diagnosis and proper management is important for a patient's quality of life. The first step for those with HS is to speak to their dermatologist to get an accurate diagnosis."

To learn more about HS from these specialists, go to www.RecognizinghS.com/HSO5

\section{WHEN YOU SEE THESE LESIONS, DO YOU SUSPECT HS? DO YOU ASK ABOUT RECURRENCE?}

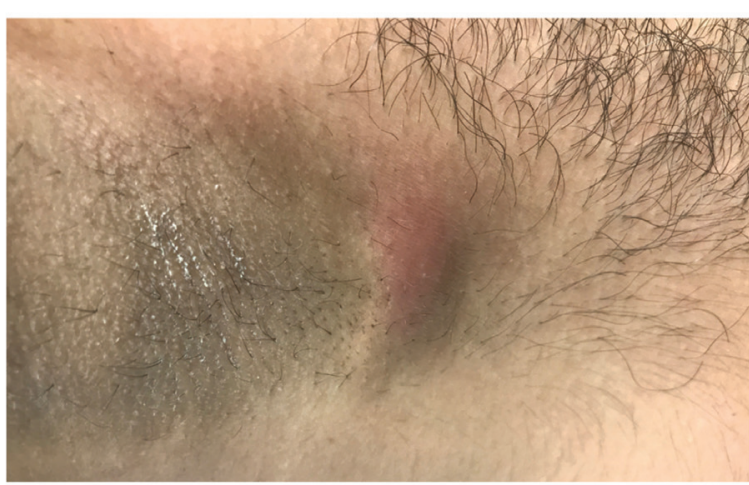

Photo compliments of Dr. Afsaneh Alavi.

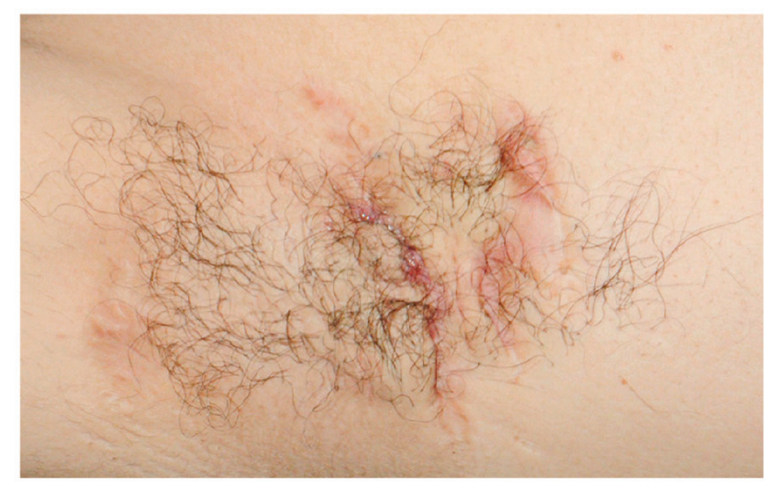

Photo compliments of Dr. Marc Bourcier.

\section{ASSESSING PATIENTS WITH RECURRENT BOILS}

Most HS cases can be recognized with high reliability by the presence of 3 main features: ${ }^{1-3}$

1. Typical lesions: nodules, sinus tracts, abscesses, scarring

2. Typical anatomical location: axilla, groin, genitals, under the breasts, others (perianal, neck, abdomen, buttocks)

3. Relapses and chronicity: $\geq 2$ times per 6 months
Questions to ask your patients with suspected HS:?

1. Have you had outbreaks of boils during the last 6 months?

2. Where were the boils and how many did you have?

To confirm an HS diagnosis, please refer your patient to a dermatologist.

References: 1. Zouboulis CC, et al. European S1 guideline for the treatment of hidradenitis suppurativa/acne inversa. JEADV 2015;29:619-44. 2. Lockwood SJ, et al. Diagnostic workup. In: Kimball AB, Jemec GBE, eds. Hidradenitis Suppurativa: A Disease Primer. Cham, Switzerland: Springer; 2016:27-37. 3. Poli F, et al. Clinical presentation. In: Jemec GBE, Revuz J, Leyden JJ, eds. Hidradenitis Suppurativa. Berlin, Germany: Springer; 2006:11-24. 


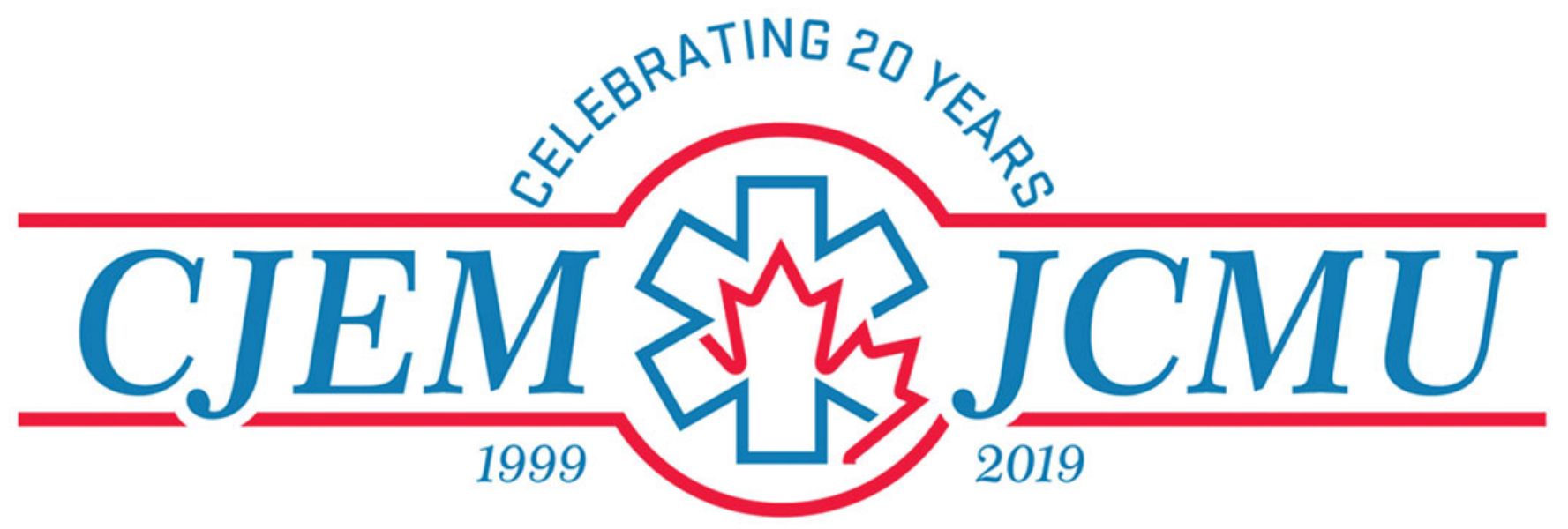

Vol. 22, No. 1

January 2020/janvier 2020

cjem-online.ca

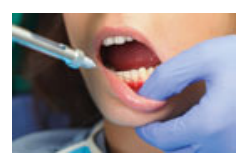

For CJEM's next audio summary describing the best editorials and articles in this January issue, visit https:// soundcloud.com/user124260332/cjem-january-2020 (English) and https:// soundcloud.com/user124260332/audio-summaryjanuary-2020-french (French).

\section{Table of Contents • Table des matières}

\section{EDITORIAL・ÉDITORIAL}

1 Ultrasound at the point of care - Grown up and moving out! Paul Olszynski, Claire Heslop, Paul Atkinson, David Lewis, Daniel J. Kim, Chau Pham, Brandon Ritcey

3 When the system comes together to solve emergency department flow Shawn Mondoux

6 Preparing the emergency departments for the "Silver Tsunami" Marcel Émond

8 A Call to Action: The Future of Simulation-based Research in Emergency Medicine in Canada Adam Cheng, Farhan Bhanji

\section{COMMENTARY • COMMENTAIRE}

11 CJEM to create a dedicated section for Quality Improvement and Patient Safety Publication

Shawn Mondoux, Samantha Calder-Sprackman, Jennifer Thull-Freedman, Lucas B. Chartier

\section{CJEM DEBATE SERIES • SÉRIE DE DÉBATS JCMU}

14 CJEM Debate Series: \#TropandGo - Negative high sensitivity troponin testing is safe as a final test for most emergency department patients with chest pain

Andrew D. McRae, James E. Andruchow, Frank X. Scheuermeyer, Jim Christenson, Paul Atkinson

\section{JUST THE FACTS • SEULEMENT LES FAITS}

19 Just the Facts: Diagnosis and treatment of diabetic ketoacidosis in the emergency department

Justin W. Yan, Tamara Spaic, Selina Liu 


\section{NEED TO KNOW: CJEM JOURNAL CLUB • BESOIN DE SAVOIR: CLUB DE LECTURE JCMU}

27 Do systemic antibiotics for skin and soft tissue abscesses after incision and drainage improve cure rates compared with placebo? A critical appraisal

James Ahlin, Melanie Walker, David Messenger

29 Journal Club: Dual antiplatelet treatment in TIA and high-risk ischemic CVA, a review of the POINT trial Margaret Hull

31 Is Intranasal Ketamine Safe and Effective as a Prehospital Analgesic? Brett H. Shaw, Marshall Ross

33 Does the CATCH clinical decision rule adequately determine which children with minor head injury require computed tomography (CT) imaging?

Miles Hunter, Nicholas Packer, Shawn Dowling

\section{CAEP PAPER • PAPIER ACMU}

36 CAEP Dental Care Statement Hasan Sheikh

40 Health human resources for emergency medicine: a framework for the future Douglas Sinclair, Peter Toth, Alecs Chochinov, John Foote, Kirsten Johnson, Jill McEwen, David Messenger, Judy Morris, Paul Pageau, David Petrie, Carolyn Snider

\section{SYSTEMATIC REVIEWS • ARRÊT CARDIAQUE}

45 Long-term outcomes in syncope patients presenting to the emergency department: A systematic review Cameron W. Leafloor, Patrick Jiho Hong, Muhammad Mukarram, Lindsey Sikora, Jesse Elliott, Venkatesh Thiruganasambandamoorthy

56 Interventions to reduce emergency department consultation time: A systematic review of the literature Weiwei Beckerleg, Krista Wooller, Delvina Hasimjia

\section{GERIATRICS・GÉRIATRIES}

65 Frailty and adverse outcomes in older adults being discharged from the emergency department: A prospective cohort study Jonathan Afilalo, Salvatore Mottillo, Xiaoqing Xue, Antoinette Colacone, José A. Morais, J. Scott Delaney, Marc Afilalo

74 Examining the relationship between triage acuity and frailty to inform the care of older emergency department patients: Findings from a large Canadian multisite cohort study Fabrice Mowbray, Audrey-Anne Brousseau, Eric Mercier, Don Melady, Marcel Émond, Andrew P. Costa

\section{PREHOSPITAL CARE・SOINS PRÉHOSPITALIERS}

82 Decreasing time to first shock: Routine application of defibrillation pads in prehospital STEMI Sarah Felder, Kristine VanAarsen, Matthew Davis

86 Population-based analysis of the effect of a comprehensive, systematic change in an emergency medical services resource allocation plan on 24-hour mortality John M. Tallon, Lu Zheng, Julie Wei, William Dick, George Papadopoulos, Ognjenka Djurdjev 


\section{EDUCATION・ENSEIGNEMENT}

95 The competency-based medical education evolution of Canadian emergency medicine specialist training Jonathan Sherbino, Glen Bandiera, Ken Doyle, Jason R. Frank, Brian R. Holroyd, Gord Jones, Joanne Norum, Carolyn Snider, Kirk Magee

103 Simulation-based research in emergency medicine in Canada: Priorities and perspectives Timothy Chaplin, Brent Thoma, Andrew Petrosoniak, Kyla Caners, Tamara McColl, Chantal Forristal, Christa Dakin, Jean-Francois Deshaies, Eliane Raymond-Dufresne, Mary Fotheringham, David Ha, Nicole Holm, James Huffman, Ann-Marie Lonergan, George Mastoras, Michael O'Brien, MarieRose Paradis, Nicholas Sowers, Errol Stern, Andrew K. Hall

112 An international, interprofessional investigation of the self-reported podcast listening habits of emergency clinicians: A METRIQ Study Brent Thoma, Scott Goerzen, Timothy Horeczko, Damian Roland, Andrew Tagg, Teresa M Chan, Stevan Bruijns, Jeff Riddell, The METRIQ Podcast Study Collaborators

\section{CASE REPORTS • RAPPORTS DE CAS}

118 Use of telemedicine in the management of life-threatening periorbital necrotizing fasciitis in a remote community Parsa Mehraban Far, Jacob Rullo, Vladimir Kratky

121 Diarrhea and delirium from naltrexone-precipitated opioid withdrawal Isabelle Miles, Andrew Kestler, Frank X. Scheuermeyer

\section{HUMANITY・HUMANITÉ}

123 In Stride Alicia Cundall

125 Priorities: Reflections on an invaluable clinical lesson Jonathon Broughton

\section{GLOBAL RESEARCH HIGHLIGHTS • FAITS MARQUANTS DE LA RECHERCHE MONDIALE}

\section{Global Research Highlights}

